\title{
MERIDIONAL SEA-ICE TRANSPORT AND ITS IMPACT ON CLIMATE
}

\author{
by
}

\author{
Tamara Shapiro Ledley
}

(Department of Space Physics and Astronomy and the Earth Systems Institute, Rice University, P.O. Box 1892, Houston, TX 77251 , U.S.A.)

\section{ABSTRACT}

Sea ice is an important factor in controlling the ocean-atmosphere energy exchange in polar regions, and has an important impact on climate. This is because sea ice insulates the relatively warm ocean from the cold winter atmosphere, and has a higher surface albedo than the ocean. In this study the effect of sea-ice transport on the energy exchange between the atmosphere and ocean, and thus on climate, is examined using a coupled energy-balance climate -thermodynamic sea-ice model.

Transport of sea ice produces a thinning of the zonally annually-averaged sea ice in the poleward-most zones, and an extension of the ice edge equatorward. Thinning of the poleward-most ice produces an increase in the annual sensible heat flux from the ocean to the atmosphere, which produces an increase in the mean annual atmospheric temperatures. Sensible heat flux is decreased in the zones that contain the ice edge. However, warming in the poleward-most zones produces an increased meridional energy convergence at the ice edge that offsets the decrease in the sensible heat flux to the atmosphere, resulting in a net warming.

\section{INTRODUCTION}

The ocean-atmosphere energy exchange is an important factor in determining the climate of the Earth. The existence of sea ice at the ocean surface alters this exchange because sea ice insulates the relatively warm ocean from the cold winter atmosphere, and has a significantly higher surface albedo than the open ocean. The net impact of sea ice on the surface energy exchange depends on its latitudinal extent, thickness, snow cover, impurities, and concentration. Effects of some of these factors have been examined in various studies using climate models; however, the importance of the individual energy fluxes in producing climate change, and the role of sea ice and leads in modifying those fluxes, has only begun to be investigated (Ledley, 1988a, b, c).

In Thorndike (1975), Maykut $(1978,1982)$ and Ledley $(1988 \mathrm{a}, \mathrm{b}, \mathrm{c})$, the importance of sea ice and its concentration in controlling the magnitude of surface energy fluxes was demonstrated. In this study sea-ice transport is added to the coupled energy-balance climate-thermodynamic sea-ice model (the CCSI model) used in Ledley (1988a, b, c). The effect of this transport on mean annual sea-ice thickness and concentration, and thus on the annually averaged oceanatmosphere energy exchange and mean annual air temperature is examined.

\section{CCSI MODEL}

The CCSI model, described in detail in Ledley (1988c), is described only briefly here. This model treats four distinct components of the climate system, each of which is represented by a single layer. These are the air over land, the air over ocean, a mixed-layer ocean, and a ground layer. The model used in this study employs a $10^{\circ}$ latitudinal grid, with a land-sea resolution in each zone distributed in accordance with current land-sea distribution.

The CCSI model predicts the future air layer temperatures through the use of a simple explicit finite differencing scheme. The energy fluxes that are included in this calculation are the horizontal heat transports (meridional and zonal), short and long wave radiative fluxes, sensible heat flux, and latent heat flux. The horizontal energy fluxes between land and sea within a zone and between latitude zones are computed, and the horizontal fluxes between zones in the ocean are specified. Vertical energy fluxes are computed at the top of the atmosphere over ocean and land (and for short wave radiation, over sea ice), and at the surface over ocean, sea ice, and land. The model simulates seasonal cycles, a necessary feature for studying the impact of sea-ice variations on climate.

The thermodynamic sea-ice model used in the CCSI model is that described by Ledley (1985) based on the models of Semtner (1976) and Maykut and Untersteiner (1971). A three-layer thermodynamic model, it includes conduction within the ice, penetration of solar radiation into the ice layers, and surface energy balances.

The CCSI model does not explicitly compute the dynamic processes involved in lead formation. Therefore, the formation of new sea ice on open ocean and the opening and closing of leads are computed following the techniques of Ledley (1987). In this parameterization a minimum lead fraction (MLF, representing the minimum fraction of open ocean within the ice pack that is formed due to dynamic processes during the winter) of the total ice/ocean area to be occupied by leads during the winter, is specified. In addition, as described below, the transport of sea ice into equatorward latitudinal zones is included in the model.

\section{THE SEA-ICE TRANSPORT PARAMETERIZATION}

The sea-ice transport parameterization has four main parameters. These control when ice can be transported, the response of the ocean temperature to the transported ice, and also include the MLF, and the fraction of the ice displaced by the opening of the MLF that is piled on existing ice within the same zone, referred to hereafter as ridged, or that is moved into a more equatorward zone, referred to hereafter as transported.

In this study the first parameter, the fraction of ice cover that must exist for transport to occur, is $10 \%$. The volume of ice that is transported out of a zone is equal to the ice thickness $x$ ocean area $x$ ice fraction in the zone $x$ MLF $\times$ fraction of the ice moved to open the MLF that is transported into an equatorward zone.

The mixed-layer ocean may be above the freezing point when ice is transported into the zone. The transported ice will not be melted if the ocean temperature is below a value determined as a linear function of the lead fraction. The second important parameter determines the maximum value of this limiting temperature. In this study it is set such that the mixed-layer temperature can range from the freezing point, if the $10^{\circ}$ latitudinal zone is ice covered, to $10 \mathrm{~K}$ above the freezing point, if the $10^{\circ}$ latitudinal zone is ice free. If the mixed-layer temperature exceeds this 
TABLE I. MLF CASES AS A FUNCTION OF LATITUDE

Latitude

MLF

$\begin{array}{lcccc} & \text { A } & \text { B } & \text { C } & \text { D } \\ 85^{\circ} & 0.3 & 0.5 & 1.1 & 4.3 \\ 75^{\circ} & 0.5 & 1.1 & 1.1 & 4.3 \\ 65^{\circ} & 1.1 & 2.2 & 1.1 & 4.3 \\ 55^{\circ} & 2.2 & 3.3 & 1.1 & 4.3 \\ 45^{\circ} & 3.3 & 4.3 & 1.1 & 4.3\end{array}$

limiting temperature when ice is transported into the zone, the excess energy available for melting the ice in the zone is computed as a function of the difference between the ocean temperature and the limiting temperature. This energy is used to melt the transported ice from the edge, and the mixed-layer temperature is set to the limiting value. If all the transported ice is melted away, the remaining excess energy is assumed to maintain the mixed-layer temperature above the limiting value by an amount that maintains energy balance.

When ice is transported into a zone in which ice already exists, a new single ice thickness and ice layer temperatures are computed by volume averaging the ice transported into the zone and the ice remaining in the zone after ice transport out of that zone has occurred. Then the energy available from the ocean for the lateral melting ice is computed, and if any, the ice is melted from the edge.

The third parameter, MLF, is a function of latitude, and increases from $0.3 \%$ at the poles in the base case, $\mathrm{A}$ (see Table I for additional cases).

The fourth parameter is the partitioning factor, ranging from 0 to 1 , which determines the fraction of the ice displaced by the opening of the MLF that is transported to the next equatorward zone. This parameter is also a linear function of latitude in this study, ranging from 0.2 at the poles $(20 \%$ of the ice that is replaced by the opening of the MLF is transported to the next equatorward zone and $80 \%$ is ridged onto existing ice within the same zone) to 0.6 at $45^{\circ}$ latitude $(60 \%$ transported to the next zone, $40 \%$ ridged in the same zone).

This parameterization seems to do well in producing realistic sea-ice thicknesses in the poleward-most zones (Fig. 1). The seasonal variations in the sea-ice extent range from $50^{\circ} \mathrm{N}$ and $50^{\circ} \mathrm{S}$ to $80^{\circ} \mathrm{N}$ and $70^{\circ} \mathrm{S}$ respectively. The

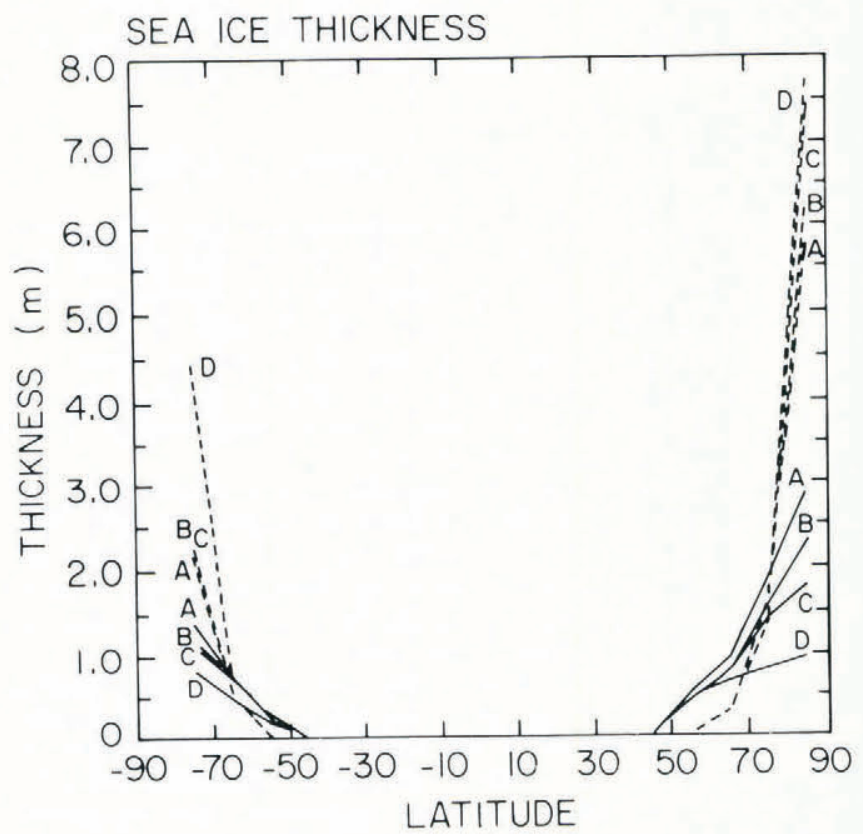

Fig. 1. Mean annual sea-ice thickness as a function of latitude when sea-ice transport is included (solid lines) and neglected (dashed lines) for the various MLF cases (see Table I for case definitions). ability of the sea-ice transport parameterization to produce realistic variations in sea-ice extent in the current formulation of the model is hard to determine because of the coarse grid used in the model; however, the variations indicated above are of the right order of magnitude. Instituting a finer grid size may refine the simulated variations in sea-ice extent.

A more complete description of the sea-ice transport parameterization is given in Ledley (1989).

\section{THE EFFECT OF SEA-ICE TRANSPORT ON SEA ICE AND TEMPERATURE}

Climatic simulations were made with the CCSI model to determine the impact of sea-ice transport, and variations in the magnitude of that transport as defined by the MLF, on climate. This was done through two series of experiments in which the MLF was varied in accordance with Table I. In one series sea-ice transport was included, and in the other it was neglected.

Figure 1 shows that while changes in the MLF have a large impact on the sea-ice thickness, the effect of the transport of sea ice is much larger. When transport is neglected, the forced opening of leads during the winter results in a large ice growth rate, and thus thick ice in the poleward-most zones. Since the ice is constrained to remain in the latitude zone in which it is formed, the mean annual ice thickness in the poleward-most zones increases. When transport is included, some of the ice formed in the poleward-most zones is transported equatorward, where it is subjected to higher temperatures and melted. This results in thinner ice in the poleward-most zones.

Figure 2 shows how the mean annual surface air temperature is affected both by changes in the MLF and the addition of transport. The thinning of the ice in the poleward-most regions when transport is included is reflected in an increase in surface air temperatures at all latitudes. The main reason for this is that the thinner ice at $85^{\circ} \mathrm{N}$ and $75^{\circ} \mathrm{S}$ produces an increase in the summer melt, increasing the maximum lead fractions and the relative amounts of water compared to ice during the summer. This causes an increase in the flux of energy from the ocean to the atmosphere, and thus increases surface air temperatures.

The energy fluxes responsible for the effect of sea-ice transport on the mean annual surface air temperatures include the sensible and latent heat fluxes, the absorbed short wave and net long wave radiation at the surface, and the horizontal energy transports in the atmosphere.

\section{CHANGE IN SURFACE AIR TEMPERATURE}

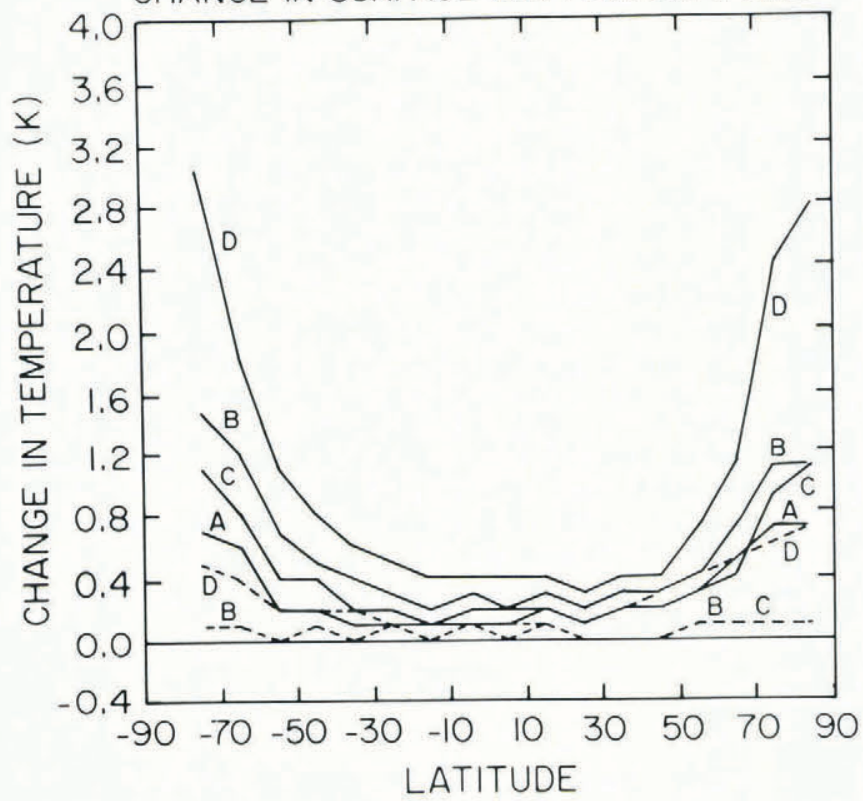

Fig. 2. Change in mean annual surface air temperature over ocean and ice as a function of latitude for each of the experiments depicted in Figure 1, from the MLF case A with no transport. Transport cases are depicted with solid lines, no-transport cases with dashed lines. 
In polar regions the energy flux most responsible for the change in the surface air temperature is sensible heat flux. This is because the sea ice is thinned most in those regions creating larger lead fractions or longer periods of relatively ice-free conditions. Since the sensible heat flux can be one to two orders of magnitude greater from the ocean to the atmosphere than from the ice to the atmosphere during the winter, larger lead fractions result in a greater sensible heat flux from the surface to the atmosphere.

In regions into which the transported ice extends, which do not form ice thermodynamically, sensible heat flux from the ocean to the atmosphere decreases. This is because of the insulating effect of the transported sea ice on the ocean surface. Latent heat flux and net long wave radiation at the surface show similar, but smaller changes as the sensible heat flux in the polar and ice edge zones.

The decrease in the energy flux from the ocean to atmosphere at the ice edge would indicate a cooling in those zones; however, Figure 2 shows a warming at all latitude zones. The reason for the warming at the ice edge in the atmosphere is the changes in the horizontal energy transport in the atmosphere. Increases in temperature in the poleward-most zones produce a smaller meridional energy convergence in those areas, and an increase in the meridional energy convergence in the zone that contains the mean annual ice edge. In that zone, which has only transported ice, this increase in the energy convergence is greater than the decrease in the turbulent heat fluxes from the ocean to the atmopshere, and the net radiative fluxes into the atmospheric layer, resulting in a net warming.

The extra energy required to produce this global warming is a consequence of an increase in the absorbed solar radiation in the climate system caused by a decrease in global surface albedo. This change in surface albedo is a result of the thinning of the poleward-most sea ice, and the resulting summer expansion of leads or the increase relative fraction of open ocean to sea ice during the summer.

Figure 1 also shows that, when transport is neglected, the mean sea-ice thickness in the poleward-most zones increases as the MLF increases; however, when the transport is included, the mean sea-ice thickness in those zones decreases as the MLF increases. The reason for this is as follows. When transport is neglected the increase in the surface air temperature between MLF case $A$ and case $D$ is $0.7 \mathrm{~K}$ at $85^{\circ} \mathrm{N}$. This is not enough to overcome the large ice growth rates during the winter, resulting in larger mean ice thicknesses. When transport is included the increase in the surface air temperature between MLF case $\mathrm{A}$ and case $\mathrm{D}$ is $2.1 \mathrm{~K}$ at $85^{\circ} \mathrm{N}$. This increased warming is large enough, along with the transport of some of the new ice equatorward, to overcome the high ice growth rate near the poles to produce thinner ice in case D than in case $\mathrm{A}$ in that region.

Previous work (Ledley, 1988a, c), which neglected sea-ice transport, showed that the model simulated surface air temperatures that were cooler than observed, especially in the Northern Hemisphere, by about $1-2 \mathrm{~K}$. Therefore, the warming produced by the sea-ice transport makes the simulation compare more favorably with observations.

\section{SUMMARY}

The results presented here show that meridional sea-ice transport and the rate of lead formation during the winter can have a significant effect on climate. The transport of sea ice produces a thinning of the ice in the poleward-most zones and an extension of the ice edge equatorward. The thinning of the poleward-most ice increases the maximum lead fraction and the period of relatively ice free conditions. This results in an increase in sensible heat flux from the ocean to the atmosphere in the poleward-most zones, which produces an increase in atmospheric temperatures. Sensible heat flux from the ocean to the atmosphere is decreased in the zones that contain the ice edge, due to increased ice coverage. However, the warming in the poleward-most zones results in an increased meridional energy convergence at the ice edge that offsets the decrease in the sensible heat flux to the atmosphere, resulting in a globally-averaged warming. The extra energy required to produce the globally-averaged warming is a result of an increase in the absorbed solar radiation produced by changes in surface albedo.

\section{ACKNOWLEDGEMENTS}

This work was supported in part by two grants from the Climate Dynamics section of the National Science Foundation, ATM-8706587 and ATM-8904437. This material is also based in part upon work supported by the Texas Advanced Technology Program under grant 3639.

\section{REFERENCES}

Ledley, T.S. 1985. Sensitivity of a thermodynamic sea ice model with leads to time step size. J. Geophys. Res., 90(D1), 2251-2260.

Ledley, T.S. 1987. Development of a new sea ice growth and lead parameterization. Climate Dynamics, 2(2), 91-100.

Ledley, T.S. 1988a. A coupled energy balance climate-sea ice model: impact of sea ice and leads on climate. $J$. Geophys. Res., 93(D12), 15,919-15,932.

Ledley, T.S. 1988b. For a lead-temperature feedback in climatic variation. Geophys. Res. Lett., 15(1), 36-39.

Ledley, T.S. 1988c. The impact of sea ice and leads on ocean-atmosphere interaction. In Seventh Conference on Ocean-Atmosphere Interactions, Jan. 31-Feb. 5, 1988 , Anaheim, CA. Boston, American Meteorological Society, 129-131.

Ledley, T.S. Submitted. The climatic response to meridional sea ice transport. Journal of Climate.

Maykut, G.A. 1978. Energy exchange over young sea ice in the central Arctic. J. Geophys. Res., 83(C7), 3646-3658.

Maykut, G.A. 1982. Large-scale heat exchange and ice production in the central Arctic. J. Geophys. Res., 87(C10), 7971-7984.

Maykut, G.A. and N. Untersteiner. 1971. Some results from a time-dependent thermodynamic model of sea ice. $J$. Geophys. Res., 76(6), 1550-1575.

Semtner, A.J., jr. 1976. A model for the thermodynamic growth of sea ice in numerical investigations of climate. J. Phys. Oceanogr., 6(3), 379-389.

Thorndike, A.S., D.A. Rothrock, G.A. Maykut, and R. Colony. 1975. The thickness distribution of sea ice. J. Geophys. Res., 80(33), 4501-4513. 